\title{
It matters to be in good hands: the relationship between good governance and pandemic spread inferred from cross-country COVID-19 data
}

\author{
Munirul H. Nabin (10 ${ }^{1}$, Mohammad Tarequl Hasan Chowdhury (iD ${ }^{2} \&$ Sukanto Bhattacharya (i]) ${ }^{1 凶}$
}

This study examines the relationship between good governance and pandemic control using month-wise COVID-19 pandemic data within a time window from April to September 2020. The study argues that countries with better governance are more capable of adopting and implementing appropriate policies and that such governments are considered more trustworthy by their people. Combined, these factors enable such countries to better control a pandemic like COVID-19. Using several measures of good governance and two measures of pandemic spread, namely the COVID-19 positive rate and the COVID-19 growth rate, this paper tests its argument econometrically in a sample of 185 countries. The results show the existence of a significant inverse relationship between all measures of good governance, and the COVID-19 positive and growth rates. The significant inverse relationship largely persists even after controlling for continent-fixed effects and a host of geographic, demographic, and socio-economic factors. This indicates the presence of a strong systemic linkage between quality of governance and pandemic control. The findings empirically strengthen the argument of eminent medical historians concerning the importance of effective governmental intervention for epidemic control. The study reveals that the quality of governance is a key factor in a country's success in pandemic management and encourages further investigation.

\footnotetext{
${ }^{1}$ Deakin University, Geelong, Australia. ${ }^{2}$ University of Chittagong, Chittagong, Bangladesh. ${ }^{凶}$ email: sukanto.bhattacharya@deakin.edu.au
} 


\section{Introduction}

ince the beginning of the COVID-19 pandemic, which has devasted the entire world, the social sciences have seen two broad strands of literature emerge, targeting the pandemic and its control. One of these strands investigates the efficacy, from both the socioeconomic and behavioral-anthropological perspectives, of specific policies or sets of policies that have been adopted by governments in an attempt to curb the pandemic; see for example, Acemoglu et al. (2021), Glaeser et al. (2020), Akesson et al. (2020), Atkinson-Clement and Pigalle (2021), Abouk and Heydari (2021) and others (interested readers are directed to Brodeur et al. (2021) for a comprehensive review of this strand of the literature).

The second and perhaps a thinner strand looks at variations in the forms of political regimes and governance as explanatory factors for the differing degrees of control that have been established over the pandemic across countries. For example, Alon et al. (2020) compared democratic and authoritarian regimes in terms of the effectiveness of their policy responses to the COVID-19 pandemic. In a similar vein, Bunyavejchewin and Sirichuanjun (2021) found that the efficacy of public policy responses to COVID-19 was related to the regime type. Perhaps more intriguingly, Toshkov et al. (2020) reported that European countries with more centralized forms of government that scored relatively poorly on measures of government effectiveness, trust, and freedom tended to respond more quickly and decisively in controlling the spread of the pandemic than decentralized countries with better scores on those measures. This obviously counter-intuitive but very interesting finding warrants deeper investigation, as it goes against the findings of prior research on the relationship between government effectiveness and epidemic control (e.g., Menon-Johansson, 2005). However, Engler et al. (2021) studied the variations in governmental policies combating COVID-19 across a sample of European democracies and found that the considerable variation cannot be explained only on the basis of pandemic-related factors, as entrenched democratic norms and institutions arguably have played a role. In fact, Liang et al. (2020) found a negative association between COVID-19 fatalities and government effectiveness, which is more consistent with intuitive notions.

The present paper investigates the relationship between good governance and control over the COVID-19 pandemic in a crosscountry setting worldwide, covering 185 countries, which is the largest number of countries considered thus far in such studies. Unlike Liang et al. (2020), who considered fatalities as the variable of interest, this paper considers the spread of the pandemic, captured through two alternative measures: the positive rate and the growth rate. Thus, it is more broad-based, as it looks at the spread of the disease, irrespective of whether or not the afflicted persons passed away as a result.

Eminent social scientists and medical historians have consistently posited that good governance, in various shapes and forms, has played a crucial role in the control of epidemics in countries around the world throughout human history (Farmer, 1999; Zakaria, 2003; Chowell and Viboud, 2016; Snowden, 2019). Menon-Johansson (2005) examined this position empirically with respect to the role of good governance in controlling the spread of human immunodeficiency virus (HIV) and found evidence that global HIV prevalence is related significantly to poor governance. A respiratory pandemic like COVID-19 may have a lower morbidity rate than AIDS, but it has much more rapid transmission chains, due to more ubiquitous modes of transmission. Intuitively then, the relationship between good governance or institutional quality and the spread of a respiratory pandemic like COVID-19 is expected to be more pronounced, given that the necessary preventative measures involve far more stringent restrictions on individuals' personal freedoms and ways of life than those required to prevent the spread of HIV. Morens and Fauci (2007) contended that gaining control over future pandemics would depend on resource availability and deployment, and the government's response to the public health crisis, more than on increased medical knowledge about treatment and prevention. The COVID-19 pandemic is a public health crisis of a magnitude to test any government's ability to rise to the occasion and exhibit its institutions' innate strength and ability to gain an upper hand over the crisis. It, therefore, presents a fertile testing ground for comprehensively testing the hypothesis about the quality of governance influencing a country's success or otherwise in getting on top of a public health crisis.

Each pandemic differs intrinsically from the previous one, and the earlier notion of 'pandemic cycles' has been discredited in the more recent literature (Kilbourne, 2004; Morens and Fauci, 2007). While there are alternative epidemiological mechanisms for predicting the emergence of future pandemics even if one discounts the 'pandemic cycles' viewpoint, a compelling argument can be made for having in place the best response preparedness, accepting the rise of a future pandemic as an inevitability. This, therefore, calls for a thorough empirical examination of whether the quality of governance can have an effect on the success or otherwise of a country in managing a pandemic, and if so, to what extent. This is what motivates the current study, given that panglobal public health crises similar to the COVID-19 pandemic are likely to occur again in the future.

"Governance consists of the traditions and institutions by which authority in a country is exercised. This includes the process by which governments are selected, monitored and replaced; the capacity of the government to effectively formulate and implement sound policies; and the respect of citizens and the state for the institutions that govern economic and social interactions among them" (Kaufmann et al., 1999, p. 1). One of the reasons why good governance can be conducive to the controlling of a pandemic like COVID-19 can be explained by the conventional epidemiological susceptibleinfected (SI) model, as proposed by Kermack and McKendrick (1927), which explains the mechanism of the spread of infectious disease. The model suggests that the number of people who are susceptible to an infectious disease is determined by the reproduction number, which in turn depends on (i) the recovery rate, that is, the rate at which an infected person becomes susceptible, and (ii) the contact rate (also known as the mobility rate), that is, the rate at which a susceptible person becomes infected. If the contact rate is greater than the recovery rate, then more people get infected, which increases the reproduction number. If the reproduction number is greater than one, this implies that one infected person transmits the disease to more than one person, meaning that the infection will spread at a higher rate. Conversely, a reproduction number smaller than one means that the spread of disease is under control. As good governance implies the adoption and implementation of public health policies that are aimed at reducing the reproduction number to below one, it can thus be hypothesized that good governance will result in greater control over the spread of a pandemic.

In the absence of a globally approved and available vaccine (and arguably for a substantial period of time following the approval and availability of a vaccine), the effective management of any global health crisis like the COVID-19 pandemic would be expected to require public health measures to remain in place that curb and control people's movements and affect their normal way of life. It is these curbs and controls that can test the faith that a country's population places in the credibility of their government's commitment. As Acemoglu et al. (2021) pointed out, the effectiveness of 
government regulations in curbing a pandemic depends on whether people are compliant with them. The rampant 'anti-lockdown' protests that have been reported in various parts of the world during the COVID-19 crisis indicate that people will be particularly unwilling to compromise on their freedom of mobility if they do not have faith in the credibility of the commitment made by their government and political leadership. Freedom of mobility is of course the most obvious aspect of normal life that will be impacted by the public health measures put in place to break the chains of transmission and curb the spread of a respiratory pandemic. Various studies have examined the efficacy of spatial analysis of population mobility, with policy implications for epidemic control in terms of putting the right response measures into place (Wei and Wang, 2020). However, a lack of faith in the credibility of the government's commitment can arguably lead to non-compliance with public health measures, thus exacerbating a crisis even if the right public health steps are taken.

Compliance with government policy requires individuals to sacrifice some of their autonomy in order to adhere to the orders of the state, and very often compliance with public health policy can be deemed an act of faith on the part of citizens (Goldstein and Wiedemann, 2021). Indeed, to be willing to sacrifice personal freedoms (especially the freedoms of mobility and social association) as a necessary part of compliance with governmental directives, citizens must have what Job (2005) refers to as 'rational trust': an innate faith which cuts across political divides and makes citizens feel that complying with governmental directives is in their own best interests rather than solely in the interests of the governing regime. This innate faith stems from public confidence in the credibility of the governmental institutions and machinery to deliver in a time of need; i.e., public confidence of being in good hands. What would inspire such an innate faith and resultant public confidence? Among other things, the past track record of the governmental institutions and machinery, in terms of how effectively they have met public expectations in delivering the desired public goods, especially at times of crisis. Therefore, one may logically hypothesize that government effectiveness may result in higher public trust and therefore higher levels of spontaneous compliance with public health directives from governmental institutions. This form of compliance, is based on public trust, is more sustainable, as it is driven not by an apprehension of retribution by the regime in power, but by an innate faith that complying with the directives will result in a direct public benefit, even though it may restrict personal freedoms. Therefore, our premise is that, in general, countries with higher levels of government effectiveness will be more successful in controlling the spread of a pandemic due to their citizens' spontaneous compliance with public health directives that may temporarily curb personal freedoms.

Our analysis uses government effectiveness, political stability, the rule of law, regulatory quality, the control of corruption, and voice and accountability as indicators of good governance. COVID-19 spread is measured by the COVID-19 positive and growth rates from April to September 2020. We specify regression equations in which the COVID-19 spread depends on an indicator of good governance. Government effectiveness is chosen as the main indicator of good governance because, by definition, it captures the most generic aspects of quality of governance, whereas the other constituents capture more specific aspects. We use cross-sectional data for 185 countries to estimate the regression equations. Our findings reveal significant negative relationships between government effectiveness and both the COVID-19 positive rate and the COVID-19 growth rate, which are seen to persist even after controlling for continent fixed effects and a number of geographic, demographic, and socioeconomic factors. The findings also remain robust to a subsample analysis and the use of alternative measures of good governance. Overall, the data shows strong evidence that effective control over a pandemic crisis will be impacted adversely by poor quality governance.

The rest of the paper is organized as follows. The next section provides details of the data, describes the variables, and illustrates the research method. The third section then presents the results of the regression analysis and discusses their implications. The fourth section presents various robustness checking exercises to support the reported results. The fifth and concluding section discusses the study's limitations and suggests a direction for future research.

\section{Research materials and methods}

Data sourcing and description of key variables. Our data on government effectiveness and other constituents of good governance, namely rule of law, regulatory quality, control of corruption, voice and accountability, and political stability, were sourced from the World Bank WGI database. We use the values for 2018. According to the World Bank, the government effectiveness variable "... captures perceptions of the quality of public services, the quality of the civil service and the degree of its independence from political pressures, the quality of policy formulation and implementation, and the credibility of the government's commitment to such policies" (World Bank, 2020). This is deemed the most broad-based, catch-all constituent of WGI with regard to the quality of governance, whereas the other five WGI constituents are more specific. This study, therefore, uses government effectiveness as its main explanatory variable, as the best single proxy for governance quality. The data on the COVID-19 positive and growth rates for the months of April to September 2020 were sourced from the WHO online database (WHO, 2020) and Our World in Data (OWID, 2020), which in turn are sourced from the Johns Hopkins University COVID-19 Dashboard. According to $\mathrm{WHO}$, the positive rate is an appropriate metric for cross-country testing adequacy because it captures the quantum of testing being done in a country relative to the size of the outbreak it is experiencing. For the purposes of this study, the positive rate is calculated as $\left(\frac{\text { Positive tests }}{\text { Total tests }} \times 100\right)$. According to WHO, a positive rate of $<5 \%$ is one of the indicators that a country has been able to get its outbreak under control. In addition to the COVID-19 positive rate, this study also considers as a secondary dependent variable the COVID-19 growth rate, which is calculated as $\left(\frac{T C_{t}-T C_{t-1}}{T C_{t-1}} \times 100\right)$, where TC stands for the total confirmed cases of COVID-19 per million of the country's population. We have used month-wise data from April to September 2020 for these two variables.

Given that COVID-19 is a respiratory infection, this study considers a number of geographic and demographic control variables, namely a country's ruggedness and latitude, whether or not it is landlocked, the distance from a country's centroid to the nearest coast/river, it's level of air pollution, the median age of its population and the percentage of the urban population. We also consider the 'polity ranking' (Polity5 project, 2018) as an additional socio-economic control variable, to account for any possible differential effects between autocratic and democratic structures of socio-political institutions. GDP per capita in PPP is also used as a control. The control variables used in this study are listed in Table 1, along with their descriptions, data sources, and years.

Our empirical analysis is based on a sample of 185 countries spread over six continents. A list of the sample of countries used in the analysis is provided in the Supplementary materials. Table 2 presents descriptive statistics for each variable in the study.

\section{Methods}

Violin plots visually illustrate the impact of government effectiveness on the dependent variables, namely the positive and growth rates of COVID-19, as described previously. Figure 1 shows violin plots of the COVID-19 positive rate data, while 
Table 1 List of the control variables used in the study with their descriptions, data sources, and years.

\begin{tabular}{|c|c|c|}
\hline Variable name & Operating description & Data source \\
\hline Ruggedness & $\begin{array}{l}\text { Topological ruggedness is captured via an index that varies from } 0 \text { to } 7 \text { : } \\
\text { the higher the index, the higher the country's ruggedness. }\end{array}$ & Nunn and Puga (2012) \\
\hline Landlock & $\begin{array}{l}\text { Dummy variable for the landlocked country: it takes a value of } 1 \text { if a } \\
\text { country is landlocked, and is } 0 \text { otherwise. }\end{array}$ & Nunn and Puga (2012) \\
\hline $\begin{array}{l}\text { Distance from centroid to } \\
\text { nearest coast/river }\end{array}$ & $\begin{array}{l}\text { Distance from the geographical centroid of a country to the nearest coast } \\
\text { or river. }\end{array}$ & Gallup et al. (1999) \\
\hline Latitude (abs.) & Absolute value of a country's latitude. & Gallup et al. (1999) \\
\hline Level of air pollution (2017 data) & PM 2.5 air pollution, mean annual exposure (microgram per cubic meter). & $\begin{array}{l}\text { World Development Indicator (WDI) } \\
\text { database of the World Bank }\end{array}$ \\
\hline Urban population (2017 data) & Percentage of a country's total population that is living in urban areas. & $\begin{array}{l}\text { World Development Indicator (WDI) } \\
\text { database of the World Bank }\end{array}$ \\
\hline Polity ranking (2018 data) & $\begin{array}{l}\text { The net result of subtracting a polity's institutionalized autocracy score } \\
\text { from its institutionalized democracy score to generate an aggregate } \\
\text { democracy variable ranging in value from }-10 \text { to } 10 \text {. The higher the rank, } \\
\text { the more democratic the country's socio-political institutions are. }\end{array}$ & Polity5 project (2018) \\
\hline Median age (2017 data) & Median age of total population. & $\begin{array}{l}\text { World development indicator (WDI) } \\
\text { database of the World Bank }\end{array}$ \\
\hline $\begin{array}{l}\text { GDP per capita (log) } \\
\text { (2018 data) }\end{array}$ & $\begin{array}{l}\text { GDP per capita, corrected for purchasing power parity (GDP-PPP), on a } \\
\text { log scale. }\end{array}$ & $\begin{array}{l}\text { World development indicator (WDI) } \\
\text { database of the World Bank }\end{array}$ \\
\hline
\end{tabular}

\begin{tabular}{|c|c|c|c|c|c|}
\hline Variable & Obs & Mean & Std. dev. & Min & Max \\
\hline Govt. effectiveness & 185 & 0.005 & 0.994 & -2.45 & 2.23 \\
\hline Ruggedness & 176 & 1.37 & 1.298 & 0.003 & 6.74 \\
\hline Landlock & 177 & 0.22 & 0.416 & 0 & 1 \\
\hline $\begin{array}{l}\text { Distance from centroid } \\
\text { to nearest cost/river }\end{array}$ & 157 & 449.126 & 558.109 & 1.043 & 3418.48 \\
\hline Latitude (abs.) & 175 & 25.719 & 17.201 & 0.446 & 64.99 \\
\hline Level of air pollution & 184 & 27.771 & 19.03 & 5.861 & 99.734 \\
\hline Urban population & 232 & 60.88 & 24.966 & 0 & 100 \\
\hline Polity ranking & 165 & 4.133 & 6.16 & -10 & 10 \\
\hline Median age & 186 & 30.553 & 9.073 & 15.1 & 48.2 \\
\hline GDP per capita (log) & 184 & 9.225 & 1.17 & 6.535 & 11.648 \\
\hline growth rate_apr & 173 & 1.705 & 1.047 & 0.02 & 5.267 \\
\hline growth rate_may & 182 & 0.885 & 0.901 & 0 & 4.234 \\
\hline growth rate_jun & 185 & 0.591 & 0.585 & 0 & 3.578 \\
\hline growth rate_jul & 185 & 0.526 & 0.533 & 0 & 3.108 \\
\hline growth rate_aug & 185 & 0.419 & 0.478 & 0 & 3.031 \\
\hline growth rate_sep & 185 & 0.300 & 0.354 & 0 & 2.759 \\
\hline positive rate_apr & 78 & 0.054 & 0.067 & 0 & 0.282 \\
\hline positive rate_may & 84 & 0.057 & 0.097 & 0 & 0.528 \\
\hline positive rate_jun & 86 & 0.072 & 0.108 & 0 & 0.541 \\
\hline positive rate_jul & 83 & 0.074 & 0.118 & 0 & 0.648 \\
\hline positive rate_aug & 93 & 0.066 & 0.086 & 0 & 0.483 \\
\hline positive rate_sep & 66 & 0.056 & 0.058 & 0 & 0.323 \\
\hline
\end{tabular}

Fig. 2 shows violin plots of the COVID-19 growth rate data. The plots are obtained by splitting the COVID-19 positive (growth) rate data into two categories: ' 0 ', which consists of COVID-19 rates from April to September 2020 for all of those countries in which the government effectiveness measure is below the global average; and ' 1 ', which consists of COVID-19 rates from April to September 2020 for those countries in which the government effectiveness measure is at or above the global average.

Each figure consists of a traditional box-and-whisker plot that shows the outlier observations along the whisker (or stem), combined with a wraparound kernel density plot. The central white spots in the violins are the medians, with the dark line through the middle representing the interquartile range. The thicker sections of the violins represent a higher probability of observations taking on a certain value relative to the thinner sections. The visual differences between the ' 0 ' and ' 1 ' categories are stark enough to allow us to posit our main hypothesis that there is a systemic difference in pandemic control between

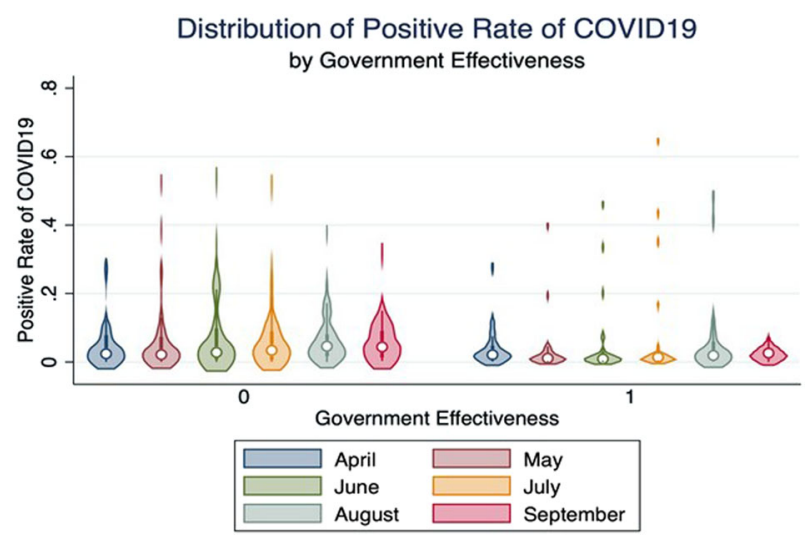

Fig. 1 Distribution of the COVID-19 positive rate by government effectiveness.

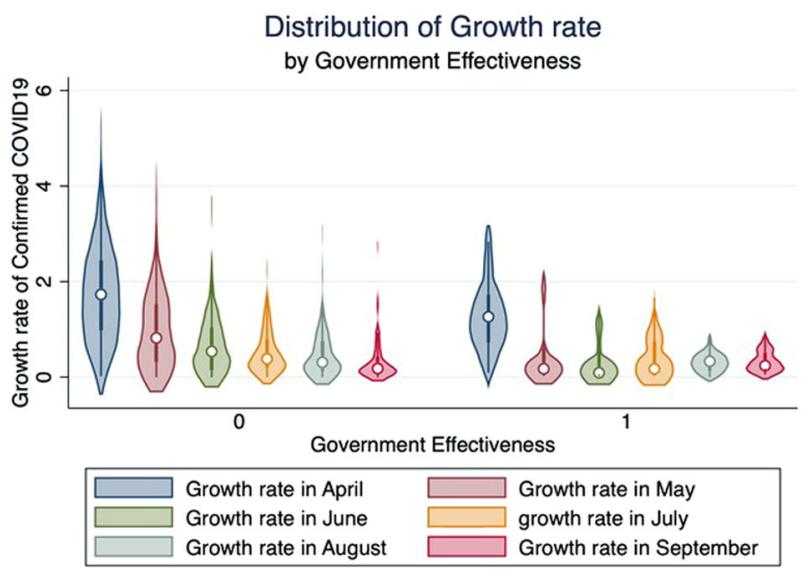

Fig. 2 Distribution of the COVID-19 growth rate by government effectiveness.

countries with higher government effectiveness and those with lower government effectiveness. In particular, it is clearly observed that the median values for the ' 1 ' category plot are lower than the median values for the ' 0 ' category, indicating a systemic 
underlying difference. Armed with this visual ratification of our main hypothesis of an inverse relationship between the quality of governance and the spread of the COVID-19 pandemic in any given country, we set up a series of regression models, as is described sequentially below.

Base model with only government effectiveness and a dummy for continent fixed effects plus an error term:

$$
\begin{aligned}
\text { positive rate }_{i}= & \beta_{0}+\beta_{1}(\text { government effectiveness })_{i} \\
& +\beta_{2}(\text { continent fixed effect dummy })_{i}+\epsilon_{i}
\end{aligned}
$$

Here (and in subsequent equations), the subscript $i$ represents each country in the sample.

Equation (1) is the base model; it hypothesizes a linear relationship between the COVID-19 positive rate and the level of government effectiveness, with no other control variables included but continent fixed effects added in. The purpose is to determine whether or not the regression coefficient associated with government effectiveness comes out as significant, and also to check whether the sign of the coefficient is indeed negative, in line with the main hypothesis.

An expanded model with four additional geographic control variables:

$$
\begin{aligned}
\text { positive rate }_{i}= & \gamma_{0}+\gamma_{1}(\text { government effectiveness })_{i} \\
& +\gamma_{2}(\text { continent fixed effect dummy })_{i}+\gamma_{3}(\text { ruggedness })_{i}+\gamma_{4}(\text { landlock })_{i} \\
& +\gamma_{5}\left({\text { distance from centroid to nearest coast } / \text { river })_{i}}\right. \\
& +\gamma_{6}\left(\text { (latitude }_{i}+e_{i}\right.
\end{aligned}
$$

Equation (2) includes all of the terms from the base model (1) plus four geographic control variables-ruggedness, landlock, distance from the centroid to nearest coast/river, and latitude. The fact that geographic features can influence the spread and severity of communicable diseases in general, and communicable respiratory diseases in particular, is well-documented in the pertinent literature (McLafferty, 2010; Hart, 2015; Pearce et al., 2017; Crocker et al., 2020). Because COVID-19 is a respiratory pandemic, we considered it necessary to include a set of geographic control variables to control for geographical variations among the countries in the data set that might impact the differential spread and progress of the pandemic.

An expanded model with additional demographic and socioeconomic control variables:

$$
\begin{aligned}
\text { positive rate }_{i}= & \phi_{0}+\phi_{1}\left({\text { government effectiveness })_{i}}\right. \\
& +\phi_{2}(\text { (continent fixed effect dummy })_{i}+\phi_{3}(\text { ruggedness })_{i} \\
& +\phi_{4}(\text { landlock })_{i}+\phi_{5}(\text { distance from centroid to nearest coast } / \text { river })_{i} \\
& +\phi_{6}(\text { latitude })_{i}+\phi_{7}(\text { level of air pollution })_{i} \\
& +\phi_{8}(\text { urban population }[\%])_{i}+\phi_{9}(\text { polity ranking })_{i} \\
& +\phi_{10}(\text { median age })_{i}+\phi_{11}(\text { GDP per capita }[\text { log }])_{i}+\xi_{i}
\end{aligned}
$$

Equation (3) includes all of the same terms as Eq. (2) plus our five demographic and socio-economic control variables-level of air pollution, urban population (\%), polity ranking, median age and GDP per capita in PPP $(\log )$.

In accordance with standard OLS assumptions, the error terms in the regression models under study are all assumed to be distributed normally with zero mean and constant variance. The control variables have been included in stages in order to allow any confounding effects of geographic vis-à-vis demographic and socio-economic factors on the base model to be isolated as much as possible. An alternative approach could start with the most comprehensive model and then apply a stepwise variable culling algorithm to finally arrive at the most parsimonious model that best fits the data. However, we decided that the approach adopted here would best reveal any differential impacts of the two different categories of control variables on the hypothesized bivariate relationship.

The level of air pollution is deemed an important control variable because several studies have indicated the existence of a positive relationship between air pollution and COVID-19 spread (Zhu et al., 2020; Frontera et al., 2020; Accarino et al., 2021). Likewise, the percentage of a country's population that lives in urban areas is considered an important control variable because, given its modes of transmission, COVID-19 is expected to spread more rapidly in places with higher population densities, such as big towns and cities, where it is relatively more difficult to maintain strict physical distancing. Polity ranking is used because the form of government can indicate the extent to which strict physical distancing and other stringent measures for controlling the spread of infection can be enforced on the country's general population. Autocratic governments with little regard for or fear of electoral backlash can enforce physical distancing, large-scale lockdowns, and other stringent measures of infection control much more harshly than democratic governments, which would be expected to take into consideration the effect of harsh measures on future electoral prospects, among other things. In regard to the median age of a country's population, prior studies have shown a direct relationship between age and susceptibility to severe cases of COVID-19 (Palmieri et al., 2020; Onder et al., 2020). However, the objective of this study is to explore the relationship (if any) between government effectiveness and measures of pandemic spread, rather than disease severity. Thus, we include the median age of a country's population to control for potential mobility, with the underlying assumption that the pandemic will spread more in countries with younger populations because they will be relatively more mobile. In line with prior studies, GDP per capita (on a log scale) adjusted for purchasing power parity (PPP) is also included in this study to control for a country's socio-economic status.

Three other regression models similar to (1)-(3) were also estimated, with the COVID-19 growth rate as the dependent variable in place of the positive rate but the same explanatory and control variables as before. The purpose of this is to lend additional support to the findings via an alternative operationalization of pandemic spread. These three additional regression models are specified below.

Base model with only government effectiveness and a dummy for continent fixed effects plus an error term:

$$
\begin{aligned}
\left(\text { growth rate }_{i}=\right. & \beta_{0}+\beta_{1}(\text { government effectiveness })_{i} \\
& +\beta_{2}(\text { continent fixed effect dummy })_{i}+\epsilon_{i}
\end{aligned}
$$

An expanded model with four additional geographic control variables:

$$
\begin{aligned}
\text { growth rate }_{i}= & \gamma_{0}+\gamma_{1}(\text { government effectiveness })_{i} \\
& +\gamma_{2}(\text { continent fixed effect dummy })_{i}+\gamma_{3}(\text { ruggedness })_{i}+\gamma_{4}(\text { landlock })_{i} \\
& +\gamma_{5}(\text { distance from centroid to nearest coast } / \text { river })_{i}+\gamma_{6}(\text { (atitude })_{i}+e_{i}
\end{aligned}
$$

An expanded model with additional demographic and socioeconomic control variables:

$$
\begin{aligned}
\text { growth rate }_{i}= & \phi_{0}+\phi_{1}(\text { government effectiveness })_{i} \\
& +\phi_{2}(\text { continent fixed effect dummy })_{i}+\phi_{3}(\text { ruggedness })_{i}+\phi_{4}(\text { landlock })_{i} \\
& +\phi_{5}(\text { distance from centroid to nearest coast } / \text { river })_{i} \\
& +\phi_{6}(\text { latitude })_{i}+\phi_{7}(\text { level of air pollution })_{i} \\
& +\phi_{8}(\text { urban population }[\%])_{i}+\phi_{9}(\text { polity ranking })_{i} \\
& +\phi_{10}(\text { median age })_{i}+\phi_{11}(\text { GDP per capita }[\text { log }])_{i}+\xi_{i}
\end{aligned}
$$

These regression models are all estimated by ordinary least square (OLS) methods. Robust standard errors are reported. For each of the dependent variables, we estimate a separate regression equation for each month from April 2020 to September 2020. An additional regression is also estimated by taking the average 
Table 3 Pairwise correlations among the six WGI constituent dimensions.

$\begin{array}{llllll}\text { Variables } & \text { (1) } & \text { (2) } & \text { (3) } & \text { (4) } & \text { (5) }\end{array}$

(1) Control of corruption 1.00

(2) Govt. effectiveness $\quad 0.92^{\star} 1.00$

(3) Regulatory quality $0.88^{\star} \quad 0.94^{\star} \quad 1.00$

(4) Rule of law $\quad 0.94^{\star} 0.94^{\star} 0.93^{\star}$

(5) Political stability

$\begin{array}{lllll}.94 * & 0.94^{*} & 0.93^{*} & 1.00 \\ .77^{*} & 0.74^{*} & 0.70^{*} & 0.76^{*} & 1.00\end{array}$

$\begin{array}{lllllll}\text { (6) Voice and } & 0.77^{\star} & 0.73^{\star} & 0.79^{\star} & 0.78^{\star} & 0.68^{\star} & 1.00\end{array}$ accountability

*Shows significance at the 0.05 level.

values of the dependent variables for six months. Although we have a maximum sample size of 185 countries, the sample size varies across regressions depending on the availability of data for the dependent and explanatory variables.

We check the robustness of the hypothesized relationship by conducting a sub-sample analysis in which we run regressions after excluding countries from Africa, Asia, Europe, North America, Oceania, South America, and the Organization of Economic Cooperation and Development (OECD) from the total sample in turn. The objective here is to check the sensitivity of our results to variations in samples. This approach also addresses a possible omitted variable bias that may be caused by the inclusion of a group of countries. We also run separate regressions using the samples of countries in Africa, Asia, Europe, and the OECD.

We refrain from using all six WGI constituents as explanatory variables in the same regression model because there are significant inter-correlations between these constituents, as Table 3 shows. Such significant inter-correlations can cause multicollinearity issues in OLS regression models. Therefore, by way of robustness checking, separate regression models have been estimated using each of the other five WGI constituents as the main explanatory variable in place of government effectiveness, with the COVID-19 positive rate as the dependent variable.

\section{Results and implications}

The pairwise correlations are shown in Table 4 inform the first three OLS regression models that use the COVID-19 positive rate from April to September 2020 as the dependent variable. The pairwise correlations are shown in Table 5 inform the next three OLS regression models that use the COVID-19 growth rate from April to September 2020 as the dependent variable.

The cross-country data distributions for the COVID-19 positive rate are shown in Fig. 3, with one panel for each of the 6 months in the period considered in the study, April-September 2020. The red dashed vertical line in each panel of Fig. 3 marks the $5 \%$ level, because a COVID- 19 positive rate of $<5 \%$ indicates that the outbreak is under control (WHO, 2020).

Figures 4 and 5 present the hypothesized relationships with the COVID-19 positive and growth rates, respectively, for the 6-month period considered in this study.

The regression results pertaining to the full models, represented by Eqs. (3) and (6), are shown in Tables 6 and 7, respectively. The regression results pertaining to the base and partial models are represented by Eqs. (1), (2), (4), and (5) are included in the Supplementary information that accompanies this paper. The results shown in Table 6 have the COVID-19 positive rate as the dependent variable and government effectiveness as the explanatory variable and include all of the control variables under both categories-geographic as well as demographic and socio-economic. Similarly, the results presented in Table 7 have the COVID-19

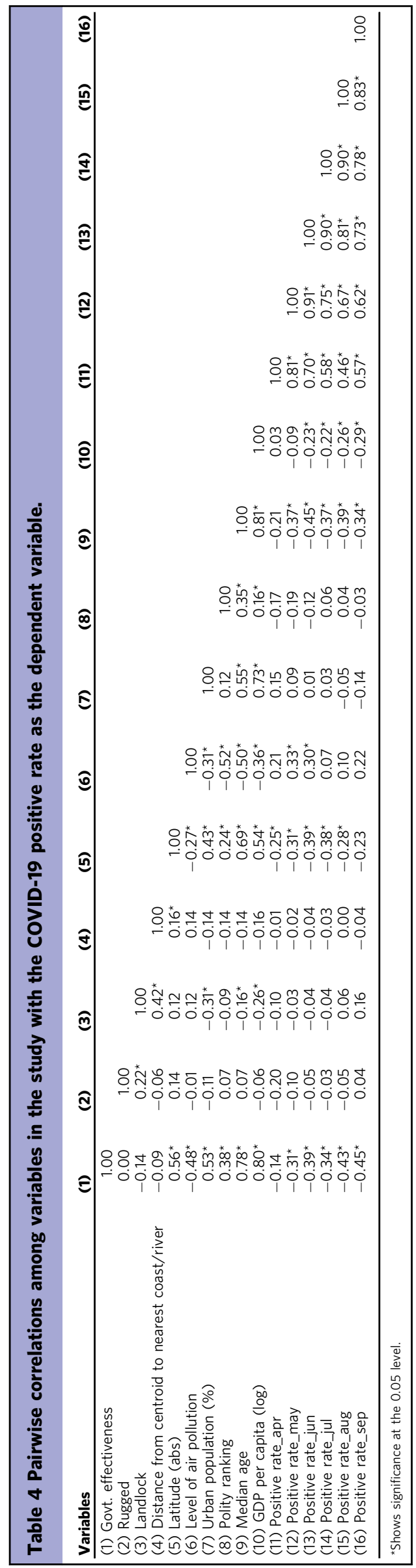




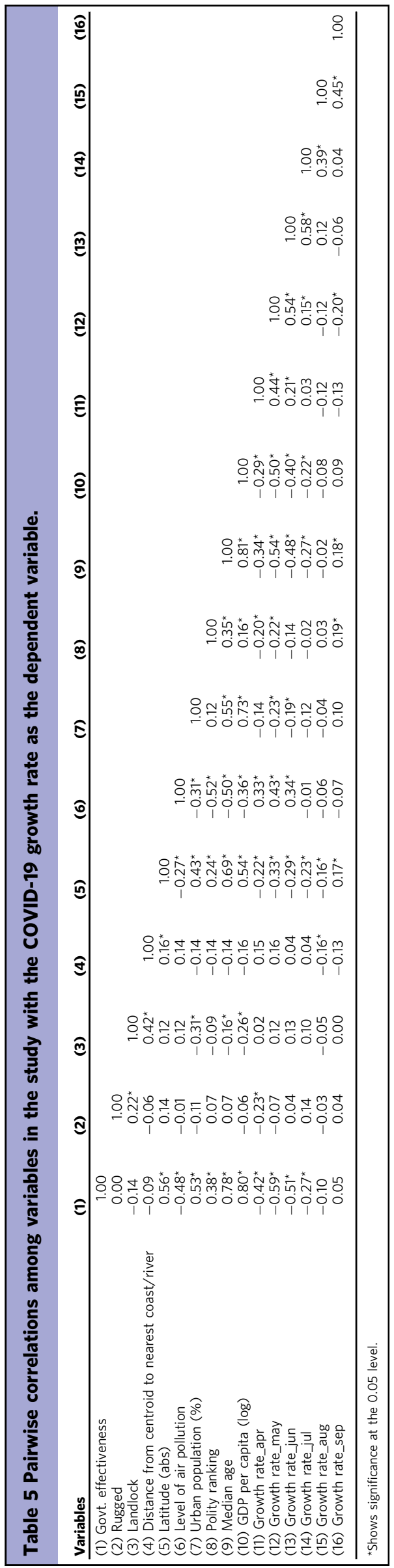

growth rate as the dependent variable and government effectiveness as the explanatory variable and include all of the control variables.

Table 6 results show that the explanatory variable government effectiveness has a statistically significant regression coefficient in five out of the 6 months that are considered in the study (columns 1-6). In addition, the coefficient is highly significant in column 7 where average values of the positive rates for six months are used as the dependent variable.

The results in Table 7 show that the explanatory variable government effectiveness has a statistically significant regression coefficient in 4 of the 6 months considered here. The coefficient estimated using the average values of the dependent variable is also highly significant. The estimated coefficient is always negative, which supports our hypothesis that better governance is associated with lower COVID-19 infections.

To put the estimated coefficient into perspective, we consider column 7 of Tables 6 and 7. For ease of interpretation of the estimated coefficient, we have calculated the beta coefficient of the explanatory variable of interest. The beta coefficient of government effectiveness is -0.45 , corresponding to the estimated coefficient reported in column 7 of Table $6 .^{1}$ This implies that, on average, one standard deviation higher level of government effectiveness is associated with a 0.45 standard deviation lower positive rate. Similarly, the corresponding beta coefficient of -0.85 from column 7 of Table 7 implies that one standard deviation higher government effectiveness is associated with an 0.85 standard deviation lower growth rate on average (Figs. 6 and 7).

Of the various controls, only the level of air pollution and the median age of the population seems to show some evidence of having any significant bearing on the COVID-19 positive and growth rates, as per the results in Tables 6 and 7 respectively. However, for the level of air pollution, neither the level of significance nor the sign of the relationship is observed to be consistent enough across the different months understudy to warrant any special attention. For the median age of the population, the relationships with both the COVID-19 positive and growth rates bear negative signs across the months in the study for which the relevant regression coefficients are observed to be statistically significant. This is consistent with the intuitive position that the lower the median age of the population (i.e., the younger the population), the higher the mobility and therefore the greater the speed of transmission. Thus, an inverse relationship can be observed between the median age of a country's population and both the COVID-19 positive and growth rates. It should be noted that this does not contradict the current medical view that older people infected with the novel coronavirus tend to have a poorer prognosis than younger people who are otherwise healthy. Older people may still be more prone to serious complications, and therefore the rate of fatality may be higher in countries with a higher median population age than in countries with a lower median age. However, we consider the positive and growth rates of COVID19 , which are indicators of pandemic spread, rather than the rate of fatality. ${ }^{2}$

We now go back to the regression results reported in Tables 6 and 7 to obtain further insights into the estimated relationship. As can be seen from Table 6, the COVID-19 positive rate retains a significant negative relationship with government effectiveness for five of the six months in the study; in fact, it shows stronger levels of significance in the later months of the study than in the earlier months. A plausible implication of these findings is that while the effect of quality of governance may take a while to crystallize in terms of specific policy measures (e.g. the daily number of COVID-19 tests conducted relative to the size of a country's population), it nevertheless offers an initial resistance to 

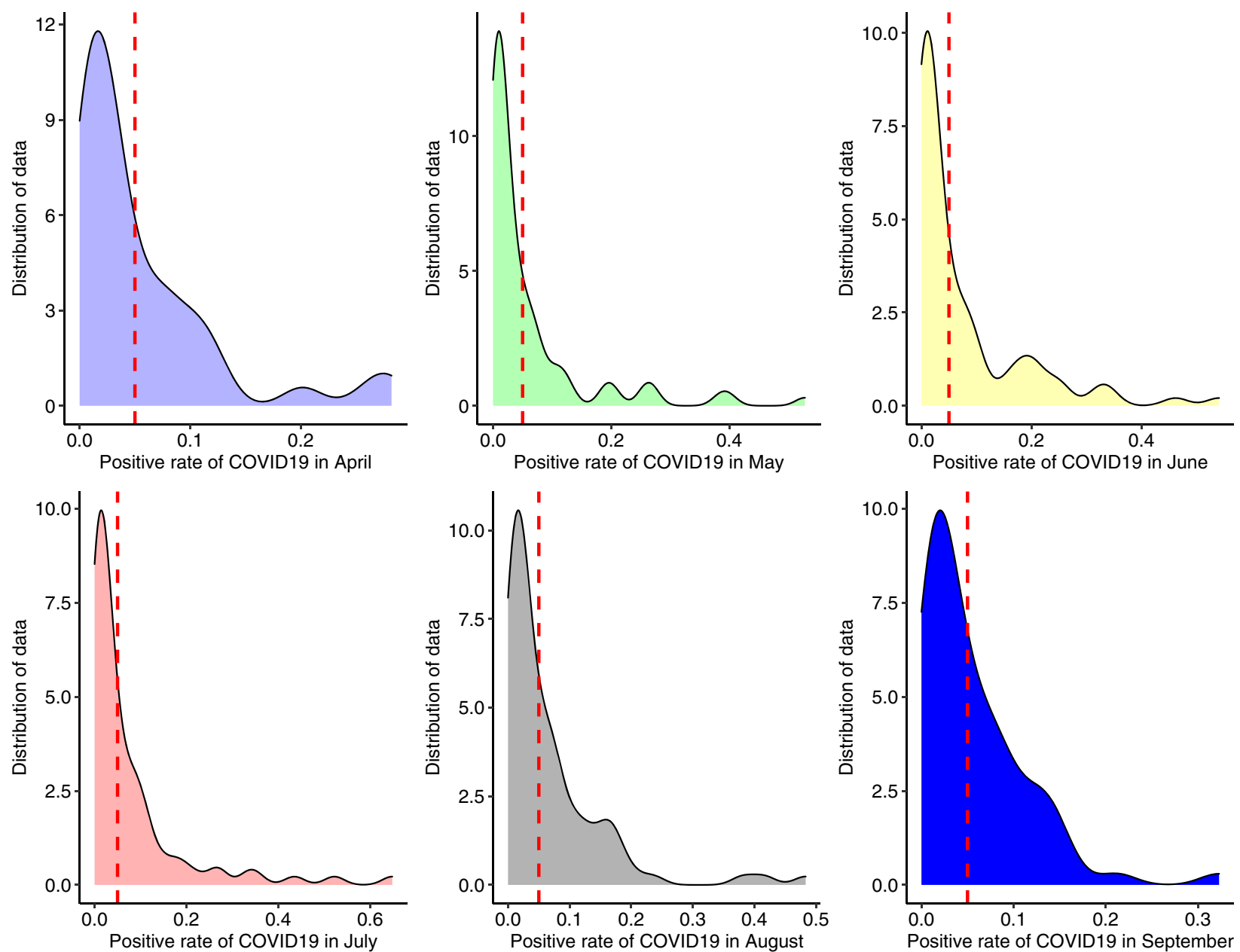

Fig. 3 Distribution of the COVID-19 positive rate across countries.

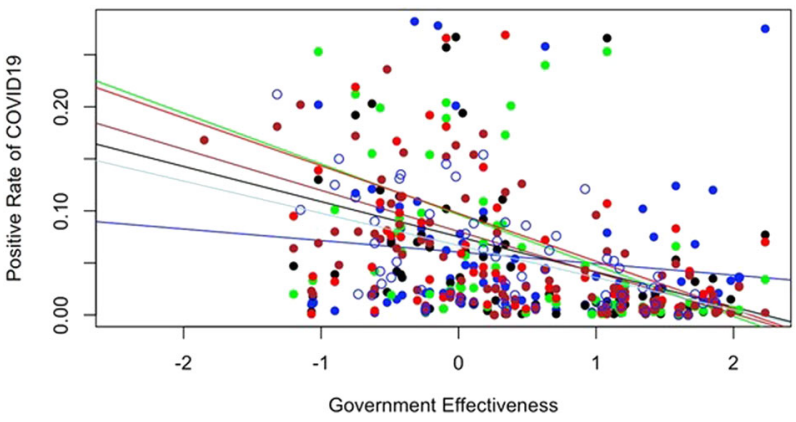

Fig. 4 The relationship between government effectiveness and the COVID19 positive rate.

the disease's growth that can probably be attributed to an inherently better allocation of administrative resources, owing to institutional efficiency.

It is interesting, however, to observe that, after showing significance in the initial months in the study, the relationship between the COVID-19 growth rate and government effectiveness in Table 7 (and also Tables S2.1 and S2.2 in the supplementary materials) abruptly becomes insignificant. The estimated coefficients also become much smaller in the later months. The most likely reason for this is that people are generally more inclined to comply with government directives on social distancing and other measures that restrict their mobility in the initial stages of the pandemic outbreak, which can be

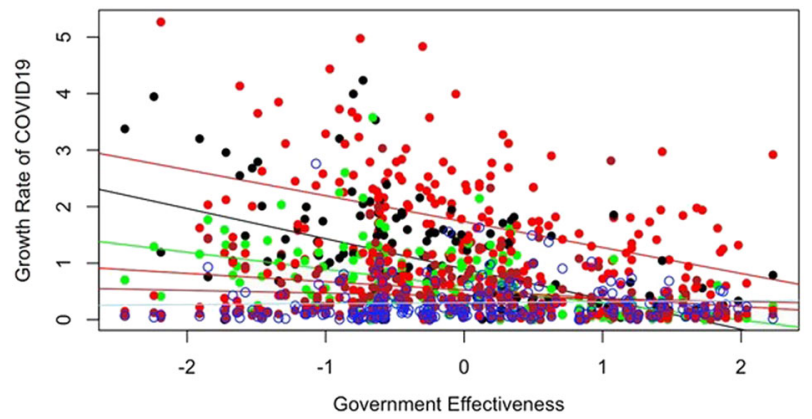

Fig. 5 The relationship between government effectiveness and the COVID19 growth rate.

attributed intuitively to the faith that a country's population places on its government's commitment. Such faith is built overtime via quality of governance. However, faith in the credibility of a government's commitment can face a tough test in the later stages of a pandemic, when people's willingness to continue complying with government directives starts to wear thin as the economic consequences of such compliance become more severe. Arguably, this may cause the pandemic growth in later stages, especially during the so-called second or third waves of the outbreak, to lose its relationship with government effectiveness to a certain degree, as people become less inclined to comply with any governmental directives that restrict their mobility. Another possible explanation for the results could be 
Predicted values of positive rate at different values of govt. effectiveness
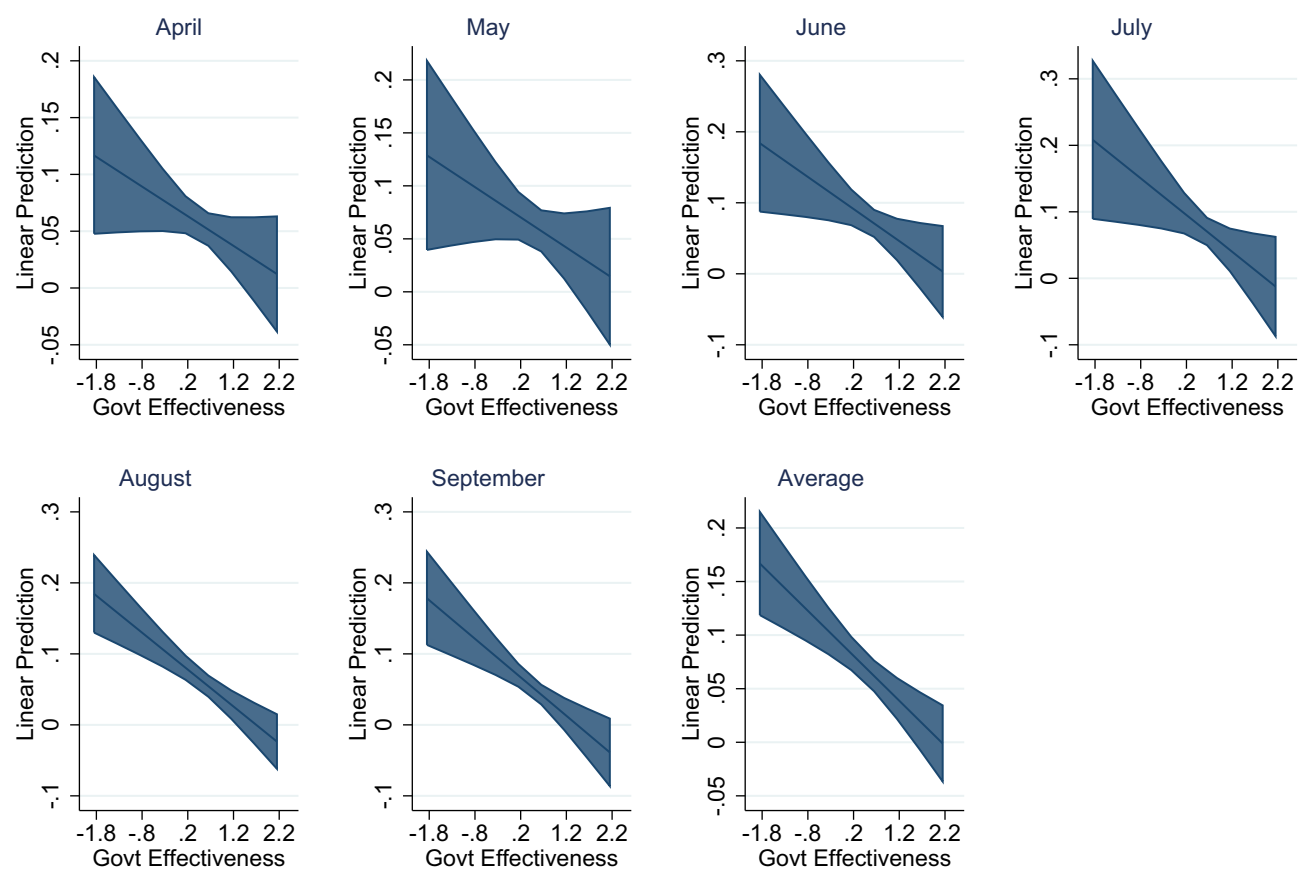

Fig. 6 Predicted values of the COVID-19 positive rate at different values of government effectiveness.

Predicted values of growth rate at different values of govt. effectiveness
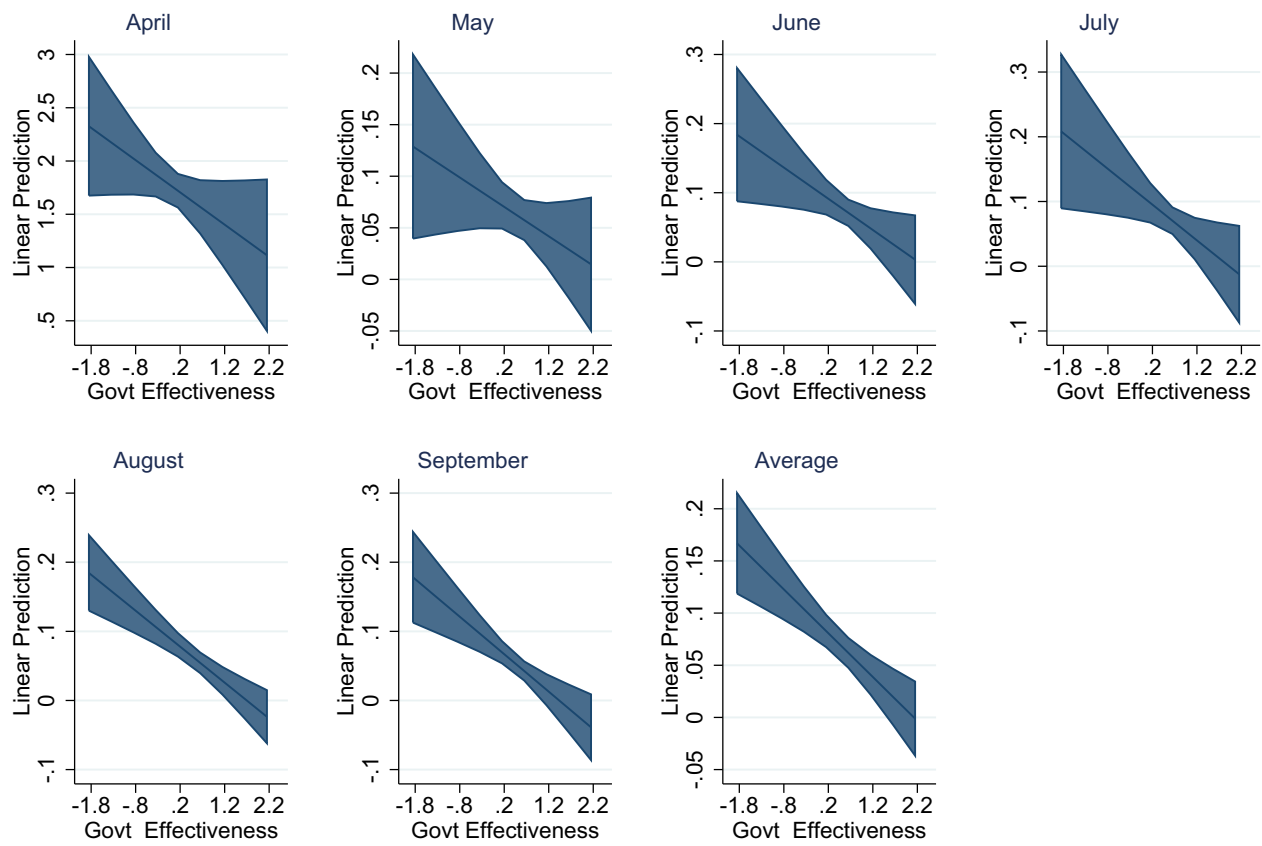

Fig. 7 Predicted values of the COVID-19 growth rate at different values of government effectiveness.

that many countries' infection curves were flattening in these months, as they were approaching the end of the so-called first wave. It is also possible that some other socio-economic or geographic variables may be playing some role in this relationship. Nevertheless, the estimated coefficients that use the 6-month average values of the dependent variable, reported in column 7 of Tables 6 and 7 , consistently show a significant negative relationship between government effectiveness and the spread of COVID-19.
Another somewhat intriguing observation that emerges from the results reported in Tables 6 and 7 is that while the estimated coefficient of government effectiveness in Table 6 gradually increases in magnitude over time, that in Table 7 decreases in magnitude over time. This could be due to the two different operationalizations of the dependent variable. While both capture the spread of COVID-19, different denominators are used in their construction: a total number of tests for the positive rate vis-à-vis the total number of confirmed cases for the growth rate. However, 

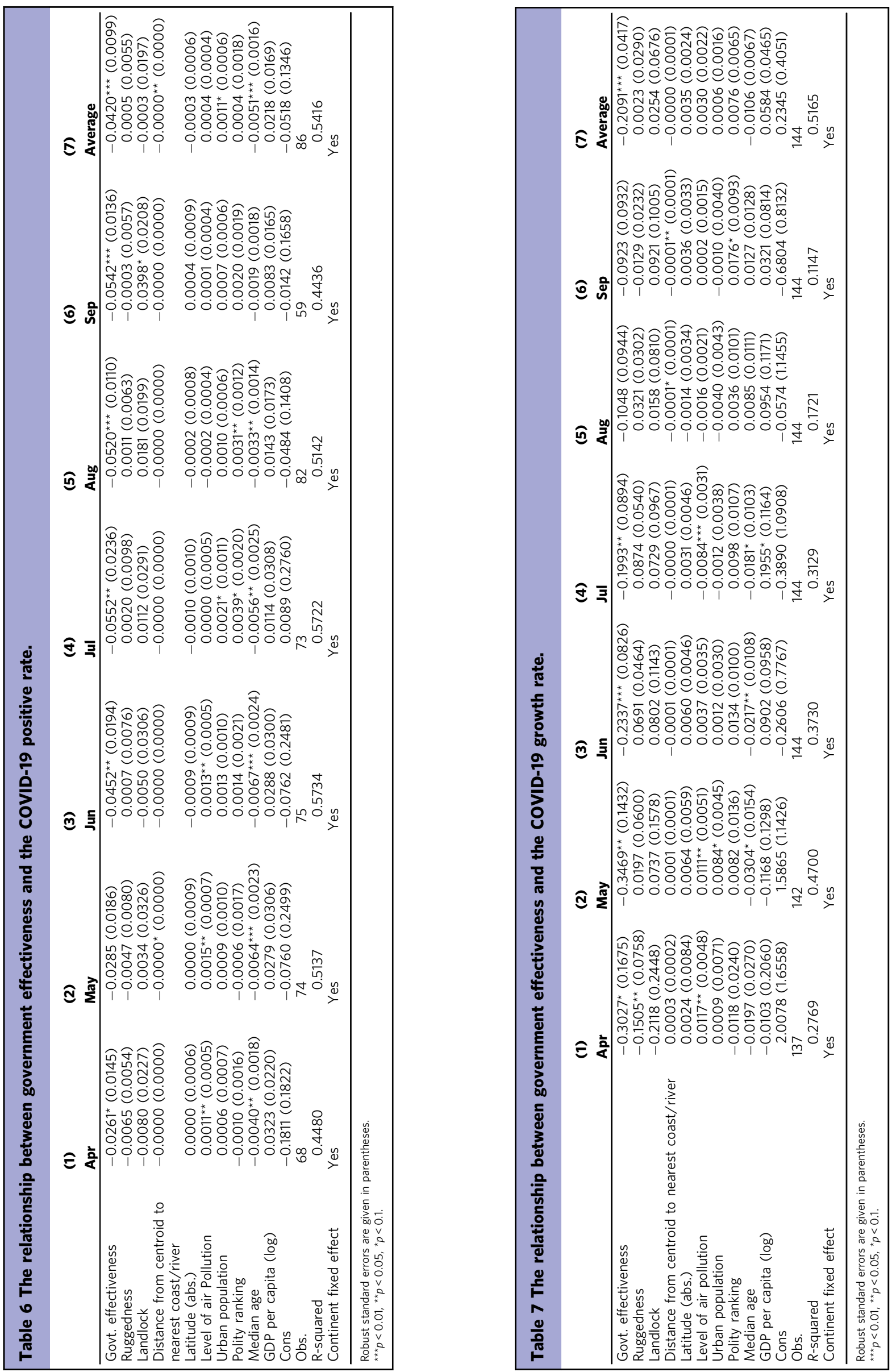
in spite of any innate variations in the alternative operationalizations of the dependent variable, the regression results are consistent in terms of the inverse relationship that is revealed between government effectiveness and pandemic spread. The strength of this finding is augmented further when average values of the dependent variable are used (see column 7 of Tables 6 and 7), which supports the idea that the relationship with government effectiveness is consistently negative irrespective of how the dependent variable of interest is operationalized.

\section{Robustness checks}

Robustness check via sub-sample analysis. We report the regression results estimated with different country sub-samples to check the robustness of the results obtained regarding the relationship between government effectiveness and COVID-19 spread. For the sake of brevity, we conduct the regression analysis using only average values of the dependent variables and report only the estimated coefficient of the main explanatory variable of interest.

Table 8 reports the regression results when the dependent variable is the average value of the COVID-19 positive rate. Thus, columns 1-7 of Table 8 are based on column 7 of Table 6 when African, Asian, European, North American, Oceanian, South American, and OECD countries, respectively, are excluded from the total sample. As can be seen from Table 8, the coefficient of government effectiveness is negative and significant at the conventional levels in all cases.

Table 9 shows the corresponding results with the average value of the COVID-19 growth rate as the dependent variable, further corroborating the results found with the alternative operationalization of the dependent variable of interest.

We now turn to regression results obtained using only the subsamples of African, Asian, European, and OECD countries, respectively. To ensure a reasonably large sample size, we conduct these analyses only for the average values of the growth rates of COVID-19 infections and consider only the African, Asian, European, and OECD sub-samples. Table 10 reports the regression results. Columns 1-4 show the results of the full model. While the estimated coefficients of government effectiveness are negative in all cases, only the African country sample shows a significant coefficient. The insignificant coefficients for the other country groups could be a result of the smaller sample size or of the greater intra-group homogeneity among the countries included in a group, which might be exacerbating the effects of multicollinearity amongst the explanatory and a number of the control variables. We investigate the latter suggestion by running the four regressions again, excluding per capita GDP (accepting the risk of an omitted variable bias). The results are presented in columns $5-8$. It can be seen that all regressions except for 6 (with the Asian sub-sample) are significant at conventional levels. This provides credence to our contention that the earlier insignificant results are attributable to multicollinearity. Overall, this sub-sample analysis supports the main finding of a significant negative relationship between government effectiveness and the spread of COVID-19. It also helps to counter the findings of Toshkov et al. (2020) that European countries with relatively lower government effectiveness were slower in their policy responses to curb COVID-19 spread.

Further robustness check using other WGI constituents as the explanatory variable. As was stated earlier, in addition to government effectiveness, there are five other constituents that make up the World Bank's WGI compilation: rule of law, regulatory quality, control of corruption, voice and accountability, and political stability. Figures $8-12$ show individual violin plots of the

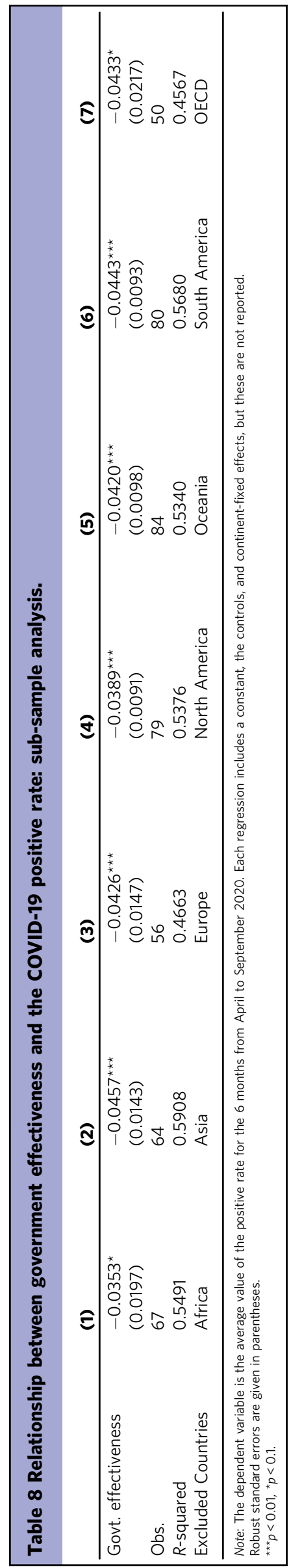




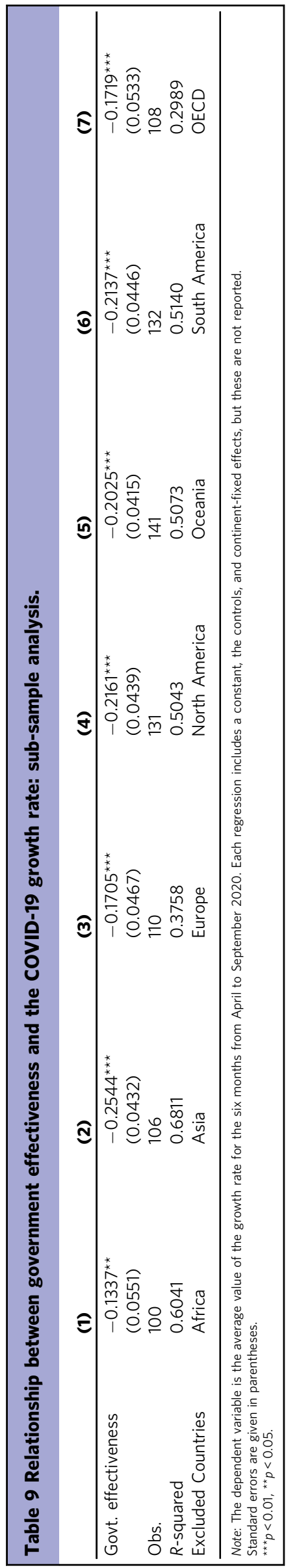

COVID-19 positive rates for each of these five WGI constituents. Again, there are two categories, ' 0 ' and ' 1 ', where ' 0 ' includes all countries that are 'below average' for the particular WGI measure and ' 1 ' includes all countries that are 'at or above average'.

The violin plots are shown in Figs. 8-12, consistent with what was seen for government effectiveness, again present visually prominent distinctions in the distribution of the COVID-19 positive rate between countries in the ' 0 ' and ' 1 ' categories, with lower medians and/or shorter interquartile ranges for countries in the ' 1 ' category than for those in the ' 0 ' category.

We conducted separate regression estimations using each of the WGI constituents (besides government effectiveness) as the main explanatory variable in turn. These additional regression results are not reported here for the sake of brevity but are included in the supplementary materials that accompany this paper. The rule of law, regulatory quality, and control of corruption all show significant negative relationships with the COVID-19 positive rate across all 6 months under study. Voice and accountability show a significant negative relationship with the COVID-19 positive rate in 4 of the 6 months understudy, while political stability shows a significant negative relationship in two of the 6 months under study. However, regardless of significance, the relationship sign is consistently negative for all of the WGI constituents across all months under study. These results further corroborate the main finding of the model reported in the previous section. The fact that voice and accountability and political stability seem to have weaker influences on the COVID-19 positive rate than the other WGI constituents may be related to the underlying dimensions of the quality of governance that those two WGI constituents are designed to capture. It could be argued that they are somewhat narrower in their focus than the other WGI constituents when it comes to capturing the quality of governance. As was pointed out earlier, our reason for choosing government effectiveness as our main explanatory variable was the fact that it is arguably the most broad-based among the various WGI constituents.

\section{Conclusion and direction for future research}

This study has empirically explored data from a large number of countries, spread across all of the major continents, to investigate the relationship between the quality of governance and the spread of COVID-19 infections. It has found statistically significant evidence of an inverse relationship between quality of governance, captured via government effectiveness and five other measures, and the spread of the COVID-19 pandemic, captured via two alternative measures, namely the COVID-19 positive rate and the COVID-19 growth rate. The study has controlled for the possible confounding effects of a number of geographic, demographic, and socio-economic factors, and found the relationship to be quite persistent, especially when using the COVID-19 positive rate as the dependent variable in the regression models. This finding corroborates similar results obtained by MenonJohansson (2005) for the global HIV epidemic, albeit using a different methodology. Thus, there is mounting statistical evidence that it does matter for the people of a country 'to be in good hands (i.e., to be administered by an effective government with a high quality of governance) when it comes to defence against epidemic outbreaks. However, at this juncture, it is important to revisit and reconcile our findings with the somewhat counter-intuitive findings reported by Toshkov et al. (2020). In a related context, Mizrahi et al. (2021) contended that, in the short run, responsiveness may in fact be valued more than trust during traumatic times, which, if true, could at least partially explain the results obtained by Toshkov et al. (2020). Indeed, Toshkov et al. (2020) themselves conceded that poorer countries with lower 
Table 10 Relationship between government effectiveness and the COVID-19 growth rate: sub-sample analysis.

\begin{tabular}{lllllllll} 
& $\mathbf{( 1 )}$ & $\mathbf{( 2 )}$ & $\mathbf{( 3 )}$ & $\mathbf{( 4 )}$ & $\mathbf{( 5 )}$ & $\mathbf{( 6 )}$ & (7) & (8) \\
\hline Govt. effectiveness & $-0.1911^{\star \star}$ & -0.0932 & -0.0654 & -0.0675 & $-0.1242^{\star}$ & -0.0847 & $-0.1955^{\star \star \star}$ & $-0.1833^{\star}$ \\
& $(0.0706)$ & $(0.0933)$ & $(0.0805)$ & $(0.0922)$ & $(0.0667)$ & $(0.0890)$ & $(0.0595)$ & $(0.0979)$ \\
Obs. & 44 & 38 & 34 & 36 & 47 & 39 & 34 & 36 \\
R-squared & 0.3478 & 0.4267 & 0.8577 & 0.6800 & 0.2086 & 0.4262 & 0.8294 \\
Sub-sample & Africa & Asia & Europe & OECD & Africa & Asia & Europe & 0.6322 \\
& & & & & &
\end{tabular}

Note: The dependent variable is the average value of the growth rate for the six months from April to September 2020. Regressions 1-4 include all of the controls, while regressions 5-8 contain all of the controls except GDP per capita in PPP (log).

Robust standard errors are given in parentheses.

${ }^{\star \star \star *} p<0.01,{ }^{\star \star} p<0.05,{ }^{\star} p<0.1$.

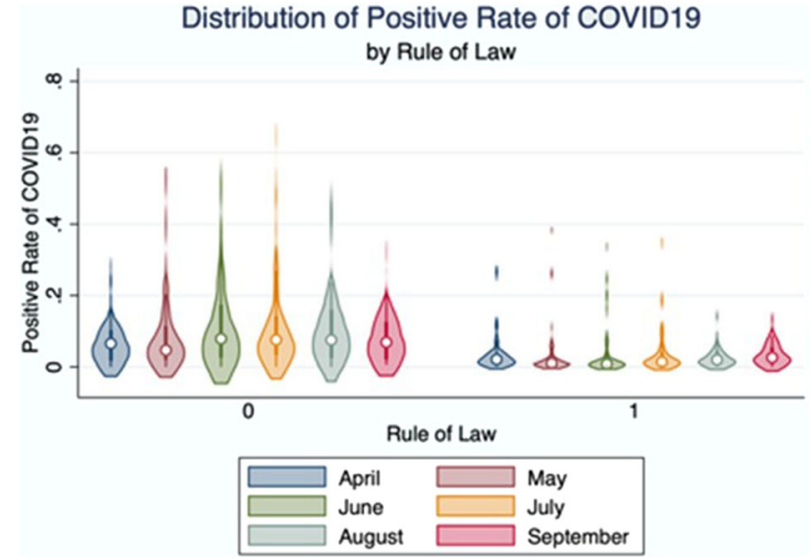

Fig. 8 Distribution of the COVID-19 positive rate by rule of law.

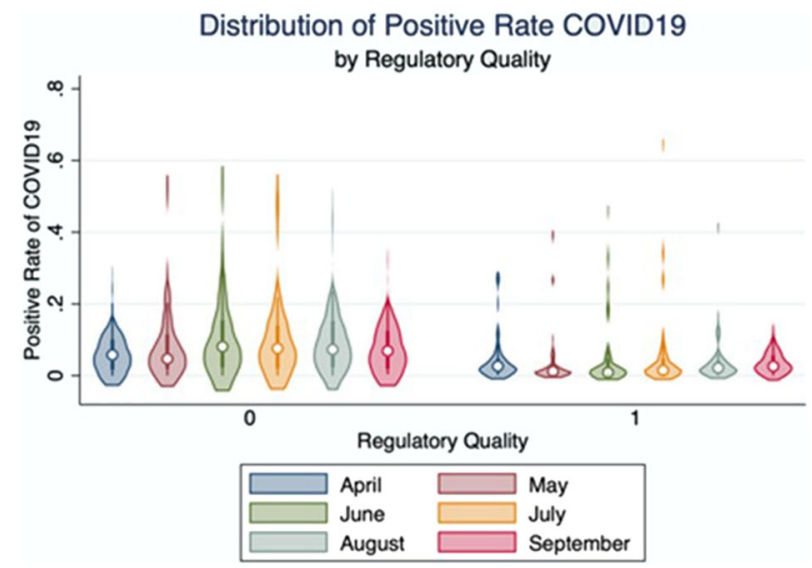

Fig. 9 Distribution of the COVID-19 positive rate by regulatory quality.

levels of government effectiveness may have realized their limited capabilities to curb a pandemic and acted "heavy-handedly", using the full force of their state-run machinery without bothering to win public trust. However, compliance that is not borne entirely out of public trust may not be truly sustainable (Pak et al. 2020). The European sub-sample analysis that was reported earlier in this paper further corroborates the intuitive relationship between government effectiveness and the spread of a pandemic.

Returning to this study, we concede two methodological shortcomings that are a result of the OLS modeling approach. Firstly, the results represent a cross-sectional view of what is essentially an evolving situation in terms of the spread of the

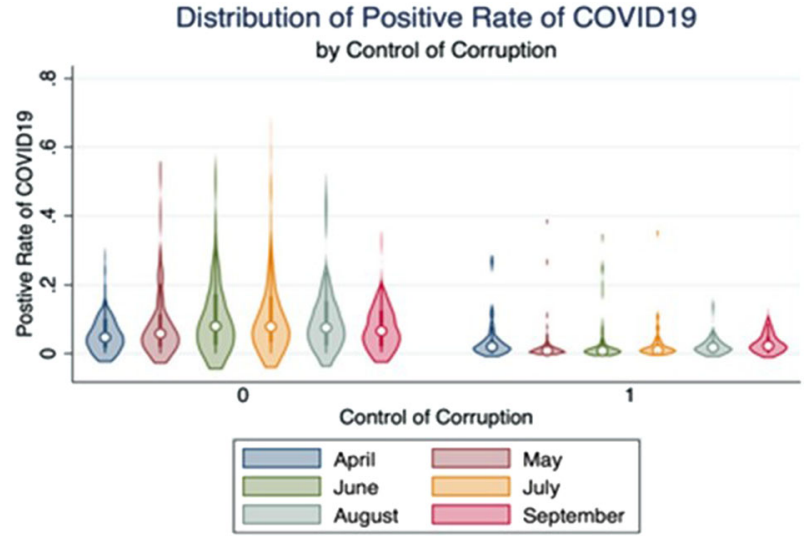

Fig. 10 Distribution of the COVID-19 positive rate by control of corruption.

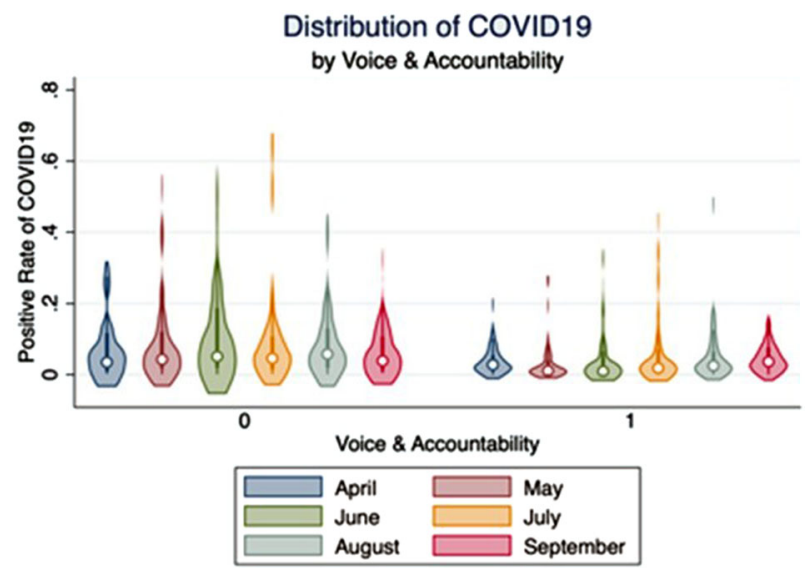

Fig. 11 Distribution of the COVID-19 positive rate by voice and accountability.

pandemic over the successive months considered in the study period. A panel data method would have been more appropriate but was not practical to implement, due to data limitations. However, the use of a cross-sectional approach does not require a major methodological compromise in this study, as neither the explanatory nor control variables are likely to show any great variations month-to-month. Secondly, as with all OLS models, the statistically significant results imply the presence of a relationship between the dependent and explanatory variables without allowing any inferences to be drawn about causality. Thus, while the results imply the existence of an inverse relationship between quality of governance and the cross-country spread of 


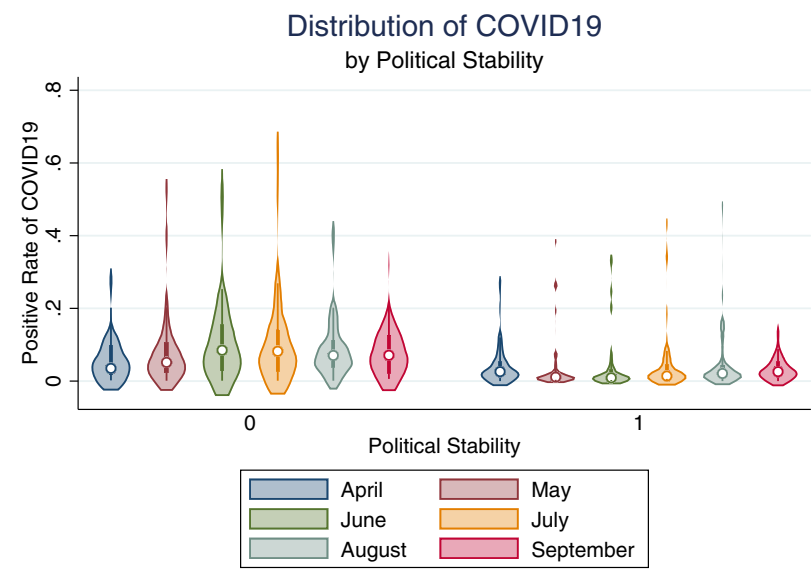

Fig. 12 Distribution of the COVID-19 positive rate by political stability.

COVID-19, one cannot say that poor governance quality 'causes' the outbreak to spread more rapidly or, conversely, that highquality governance 'causes' the spread of the outbreak to slow down. This is also inherent in the construction of the regression models in this study, as the explanatory variable is always lagged, which also protects the modeling approach from any potential 'reverse causality. However, the results justify deeper future explorations of differential effects that the variation in political institutions can have on countries' abilities to control outbreaks of communicable diseases that have quite ubiquitous modes of transmission.

\section{Data availability}

Data used in this study are publicly available. The sources of the data are mentioned in the "Methods" section of the paper. Further information about the data is available from the corresponding author on reasonable request.

Received: 20 December 2020; Accepted: 29 July 2021;

Published online: 24 August 2021

\section{Notes}

1 The beta coefficient or standardized coefficient is calculated using the following formula. Beta coefficient $=\left(\frac{\text { Standard deviation of the explanatory variable }}{\text { Standard deviation of the dependent variable }} x\right.$ estimated $(O L S)$ coefficient $)$. In column 7 of Table 6 , the estimated coefficient of government effectiveness is -0.042 . With the standard deviation of government effectiveness and the average positive rate as 0.9433 and 0.0884 , respectively, the beta coefficient of government effectiveness is calculated as -0.45 .

2 The controls used in the regressions may affect the hypothesized relationship, meaning that the appropriate measurement of the controls can be an issue. Here, we focus on a particular control, the polity ranking (Polity2), which captures the extent to which a political regime is democratic, and is an important control in this study. However, some experts have suggested the use of an alternative measure of democracy, proposed by the V-Dem project (Varieties of Democracies) (Lindberg et al., 2014). Accordingly, we have cross-checked our results by using electoral democracy, which is the main measure of democracy proposed by V-Dem, as an alternative measure of democracy. We found that Polity2 is in fact highly correlated with this V-Dem measure, with a correlation coefficient of 0.82 . Nonetheless, we re-estimated the regressions in Tables 6 and 7 by replacing the Polity 2 variable with V-Dem's electoral democracy measure. The results, which are reported in Tables A1 and A2 of the appendix included in the Supplementary materials, remain qualitatively the same; that is, the sign of the estimated coefficient of government effectiveness is consistently negative. However, the significance of the coefficient is somewhat attenuated. This could be due to multicollinearity issues, as electoral democracy is highly correlated with the explanatory variable of interest, government effectiveness. V-Dem's electoral democracy measure has a correlation coefficient with government effectiveness of 0.62 , while the correlation coefficient between Polity2 and government effectiveness is nearly half that, at only 0.36 .

\section{References}

Abouk R, Heydari B (2021) The immediate effect of COVID-19 policies on socialdistancing behavior in the United States. Public Health Rep 136(2):245-252

Accarino G, Lorenzetti S, Aloisio G (2021) Assessing correlations between shortterm exposure to atmospheric pollutants and COVID-19 spread in all Italian territorial areas. Environ Pollut 268(Part A): https://doi.org/10.1016/ j.envpol.2020.115714

Acemoglu D, Chernozhukov V, Werning I, Whinston MD (2021). Optimal targeted lockdowns in multi-group SIR model. Am Econ Rev (forthcoming).

Alon I, Farrell M, Li S (2020) Regime type and COVID-19 response. FIIB Bus Rev $9(3): 152-160$

Akesson J, Ashworth-Hayes S, Hahn R, Metcalfe RD, Rasooly I (2020). Fatalism, beliefs, and behaviors during the COVID-19 pandemic. Working paper 27245. NBER. https://doi.org/10.3386/w27245. Last retrieved 21 May 2021.

Atkinson-Clement C, Pigalle E (2021). What can we learn from Covid-19 pandemic's impact on human behaviour? The case of France's lockdown. Humanit Soc Sci Commun 8(81): https://doi.org/10.1057/s41599-021-00749-2

Brodeur A, Clark AE, Fleche S, Powdthavee N (2021) COVID-19, lockdowns and well-being: evidence from Google Trends. J Public Econ 193: https://doi.org/ 10.1016/j.jpubeco.2020.104346

Bunyavejchewin P, Sirichuanjun K (2021) How regime type and governance quality affect policy responses to COVID-19: a preliminary analysis, Heliyon 7: https://doi.org/10.1016/j.heliyon.2021.e06349

Chowell G, Viboud C (2016) Pandemic influenza and socioeconomic disparities: lessons from 1918 Chicago. Proc Natl Acad Sci USA 113(48):13557-13559

Crocker ME, Hossen S, Goodman D et al. (2020) Effects of high altitude on respiratory rate and oxygen saturation reference values in healthy infants and children younger than 2 years in four countries: a cross sectional study. Lancet Global Health 8:362-373

Engler S, Brunner P, Loviat R, Abou-Chadi T, Leemann L, Glaser A, Kübler D (2021). Democracy in times of the pandemic: explaining the variation of COVID-19 policies across European democracies. West Eur Politics https:// doi.org/10.1080/01402382.2021.1900669

Farmer P (1999) Infections and inequalities. University of California Press, Berkeley

Frontera A, Cianfanelli L, Vlachos K, Landoni G, Cremona G (2020) Severe air pollution links to higher mortality in COVID-19 patients: the "double-hit" hypothesis. J Infect 81:255-259

Gallup J, Sachs JD, Mellinger AD (1999) Geography and economic development. Int Reg Sci Rev 22(2):179-232

Glaeser EL, Gorback C, Redding SJ (2020). How much does Covid-19 increase with mobility? Evidence from New York and four other U.S. cities. Working paper 27519. NBER https://doi.org/10.3386/w27519. Last retrieved 21 May 2021.

Goldstein DAN, Wiedemann J (2021). Who do you trust? The consequences of Partisanship and trust for public responsiveness to COVID-19 orders. Perspect Politics. https://doi.org/10.1017/S1537592721000049

Hart JC (2015) Heart disease death rates in low versus high land elevation counties in the U.S. Dose-Response 13(1):14-21

Job J (2005) How is trust in government created? It begins at home, but ends in the parliament. Austral Rev Public Aff 6(1):1-23

Kaufmann D, Kraay A, Zoido-Lobatón P (1999). Governance matters. Policy Research Working Paper 2196. The World Bank. ssrn.com/abstract $=188568$. Last retrieved 21 May 2021.

Kermack WO, McKendrick AG (1927). A contribution to the Mathematical theory of epidemics. Proc R Soc Lond Ser A 115(772):700-721.

Kilbourne ED (2004). Influenza pandemics: can we prepare for the unpredictable? Viral Immunol. https://doi.org/10.1089/vim.2004.17.350

Liang L-L, Tseng C-H, Ho HJ, Wu C-Y (2020). Covid-19 mortality is negatively associated with test number and government effectiveness. Sci Rep 10: https://doi.org/10.1038/s41598-020-68862-x

Lindberg S, Coppedge M, Gerring J, Teorell J (2014) V-Dem: a new way to measure democracy. J Democracy 5(3):159-169

McLafferty S (2010) Placing pandemics: geographical dimensions of vulnerability and spread. Eurasian Geogr Econ 51(2):143-161

Menon-Johansson AS (2005) Good governance and good health: the role of societal structures in the human immunodeficiency virus pandemic. BMC Int Health Human Rights 5(1):4-12

Mizrahi S, Vidoga-Gadot E, Cohen N (2021). How well do they manage a crisis? The government's effectiveness during the COVID-19 pandemic. Public Adm Rev https://doi.org/10.1111/puar.13370

Morens DM, Fauci AS (2007) The 1918 influenza pandemic: insights for the 21st century. J Infect Dis 195(7):1018-1028

Nunn N, Puga D (2012) Ruggedness: the blessing of bad geography in Africa. Rev Econ Stat 94(1):20-36 
Onder G, Rezza G, Brusaferro S (2020) Case-fatality rate and characteristics of patients dying in relation to COVID-19 in Italy. JAMA 323(18):1775-1776

OWID (2020). https://ourworldindata.org/coronavirus-source-data. Last retrieved 18 December 2020

Pak E, McBryde E, Adegboye OA (2020) Does high public trust amplify compliance with stringent COVID-19 government health guidelines? A multicountry analysis using data from 102,627 individuals. Risk Manag Healthe Policy 14:293-302

Palmieri L, Vanacore N, Donfrancesco C et al. (2020) Clinical characteristics of hospitalized individuals dying with COVID-19 by age group in Italy. J Gerontol 75(9):1796-1800

Pearce DC, McCaw JM, McVernon J, Mathews JD (2017) Influenza as a trigger for cardiovascular disease: an investigation of serotype, subtype and geographic location. Environ Res 156:688-696

Polity5 project (2018). The Polity Project. Center for Systemic Peace, http:// www.systemicpeace.org/polityproject.html. Last retrieved 18 December 2020

Snowden FM (2019) Epidemics and society: from the black death to the present. Yale University Press, New Haven

Toshkov D, Yesilkagit K, Carroll B (2020). Government capacity, societal trust or party preferences? What accounts for the variety of National Policy Responses to the COVID-19 pandemic in Europe? OSF Preprints, https:// doi.org/10.31219/osf.io/7chpu, last retrieved 21 May 2021

Wei S, Wang L (2020). Examining the population flow network in China and its implications for epidemic control based on Baidu migration data, Humanit Soc Sci Commun 7(145): https://doi.org/10.1057/s41599-020$00633-5$

WHO (2020) https://covid19.who.int/?gclid=EAIaIQobChMIpbfYp8Kw7QIVT3mL Ch3cDgXPEAAYASAAEgLZHPD_BwE. Last retrieved 18 December 2020

World Bank (2020) http://info.worldbank.org/governance/wgi/. Last retrieved 18 December 2020

Zakaria F (2003) The future of freedom. W. W. Norton \& Company, New York

Zhu Y, Xie J, Huang F, Cao L (2020) Association between short-term exposure to air pollution and COVID-19 infection: evidence from China. Sci Total Environ 727: https://doi.org/10.1016/j.scitotenv.2020.138704

\section{Acknowledgements}

The authors would like to gratefully acknowledge the suggestions and insights provided on an initial draft of the paper by Prof. Pushkar Maitra of Monash University, Australia.

\section{Competing interests}

The authors have no competing interests.

\section{Additional information}

Supplementary information The online version contains supplementary material available at https://doi.org/10.1057/s41599-021-00876-w.

Correspondence and requests for materials should be addressed to S.B.

Reprints and permission information is available at http://www.nature.com/reprints

Publisher's note Springer Nature remains neutral with regard to jurisdictional claims in published maps and institutional affiliations.

(c) (i) Open Access This article is licensed under a Creative Commons Attribution 4.0 International License, which permits use, sharing, adaptation, distribution and reproduction in any medium or format, as long as you give appropriate credit to the original author(s) and the source, provide a link to the Creative Commons license, and indicate if changes were made. The images or other third party material in this article are included in the article's Creative Commons license, unless indicated otherwise in a credit line to the material. If material is not included in the article's Creative Commons license and your intended use is not permitted by statutory regulation or exceeds the permitted use, you will need to obtain permission directly from the copyright holder. To view a copy of this license, visit http://creativecommons.org/ licenses/by/4.0/.

(C) The Author(s) 2021 